\title{
Research on Effect of Guiping Tongqiao Decoction and Xinqi Granule on Symptoms Improvement and Serum Th1/Th2 Levels in Patients with Allergic Rhinitis
}

\author{
Rui Wei, Muhua Liang \\ Henan Province Hospital of TCM, Henan, Zhengzhou, 450002
}

Keywords: Allergic Rhinitis; self-made Guiping Tongqiao Decoction; Xinqi Granule

\begin{abstract}
Objective: To investigate the application effect of Guiping Tongqiao Decoction combined with Xinqi Granules in patients with allergic rhinitis. Methods: Eighty-three patients with allergic rhinitis in our hospital were divided into two groups according to the random number table method. Both groups were treated with loratadine. 41 patients in the control group were given Xinqi granules on the basis of loratadine, and 42 patients were in the observation group. On the basis of the control group, Guiping Tongqiao Decoction was administered. The clinical efficacy, scores of symptoms before and after treatment (sneezing, nasal itching, runny nose), and the changes of serum immunoglobulin E (IgE) and Th1/Th2 levels were compared. And statistics the incidence of adverse reactions are in the two groups. Results: The total effective rate of the observation group was $95.24 \%$ (40/42), which was higher than $75.61 \%(31 / 41)$ of the control group $(\mathrm{P}<0.05)$. The symptoms of sneezing, nasal itching, salivation, and serum were observed in the observation group after 2 weeks of treatment. The level of $\operatorname{lgE}$ was lower than that of the control group, and the Th1/Th2 level was higher than that of the control group $(\mathrm{P}<0.05)$. The incidence of adverse reactions was $11.90 \%(5 / 42)$ in the observation group and $7.32 \%(3 / 41)$ in the control group. No statistical significance $(\mathrm{P}>0.05)$. Conclusion: Xinqi granules combined with Guiping Tongqiao Decoction can improve the serum lgE, Th1/Th2 levels in patients with allergic rhinitis, improve the clinical symptoms, and have good curative effect and high safety.
\end{abstract}

\section{Introduction}

Allergic rhinitis is a common disease in the otolaryngology department. The incidence rate is $10 \%$ to $25 \%$. With the increase of environmental pollution, the prevalence of allergic rhinitis has increased year by year [1]. When the disease is accompanied by sneezing, nasal congestion, runny nose, nasal itching and other symptoms, and has the characteristics of delayed disease, repeated attacks and other characteristics, has a great impact on the patient's daily life and work. The current clinical use of loratadine treatment, can quickly improve the patient's nasal congestion, nasal itching and other symptoms, but the drug can only play a role in the control of symptoms, relapse rate after drug withdrawal is higher. Chinese medicine has a more in-depth study of pathological pathogenesis of allergic rhinitis and considers it to be a category of "snot" or "snoring". Symptoms are in the lung, and the source is spleen and kidney deficiency. It is advocated from the theory of traditional Chinese medicine and uses poisons [2]. In this study, Gui Ping Tong Yu Tang and Xin Qi Granules were used to treat allergic rhinitis and achieved significant results. The results are reported below.

\section{Materials and Methods}

\subsection{General Information.}

Eighty-three cases of allergic rhinitis patients admitted to our hospital from February 2016 to February 2018 were grouped according to the random number table method. The control group

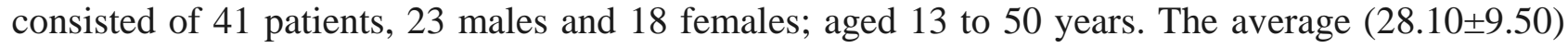
years; duration of 7 months to 8 years, average $(3.50 \pm 1.86)$ years. The observation group consisted

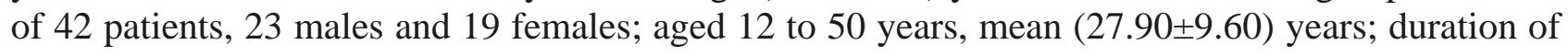


8 months to 8 years, average (3.80 \pm 1.54$)$ years. Baseline data between the two groups were not statistically different $(\mathrm{P}>0.05)$. This study was reviewed and approved by the Hospital Ethics Committee.

\subsection{Inclusion Criteria.}

(1) Conformity to the diagnostic criteria for allergic rhinitis in the "Practical Otorhinolaryngology" [3]; (2) There is no contraindication to the use of pharmaceutical ingredients in this study; (3) Informed consent of the study.

\subsection{Exclusion Criteria.}

(1) patients with chronic rhinitis, sinusitis or nasal polyps; (2) liver and kidney and other important organ failure; (3) lactating or pregnant women; (4) with cardiovascular or cerebrovascular disease; (5) Deviation of nasal septum or asthma; (6) Recent treatment with antihistamines.

\subsection{Methods.}

Oral loratadine (Shandong Tianshun Pharmaceutical Co., Ltd., Zhuozi H20051688), body mass $\leq$ $30 \mathrm{~kg}, 5 \mathrm{mg} / \mathrm{time}$, once/d; body weight $>30 \mathrm{~kg}, 10 \mathrm{mg} /$ Times, $1 \mathrm{time} / \mathrm{d}$. On the basis of the control group, the water was used to administer Xinqin Granules (Jilin Sihuan Aokang Pharmaceutical Co., Ltd., Zhunzi Z22020433), 2 g/time, 3 times/d for 2 weeks. The observation group added the self-made Gui-Ping Tongyu Decoction on the basis of the above treatment. The prescription consists of $6 \mathrm{~g}$ of wind protection, $6 \mathrm{~g}$ of cassia twig, $6 \mathrm{~g}$ of white peony, $6 \mathrm{~g}$ of magnolia, $20 \mathrm{~g}$ of scutellaria baicalensis, $10 \mathrm{~g}$ of Atractylodes and $6 \mathrm{~g}$ of white peony, finely ground. Take Shuijianbi, 1 dose/d, takes 2 times / day 1 time each morning and evening and take 2 weeks continuously.

\subsection{Serological Test.}

$4 \mathrm{ml}$ of fasting venous blood was collected and centrifuged for $10 \mathrm{~min}$. Serum Th1/Th2 levels were measured by flow cytometry using intracellular cytokine staining, and serum lgE levels were measured by immunotransmission turbidimetry.

\subsection{Rating Criteria.}

(1) Symptom score. Runny nose: The number of licking noses is 3 points per day $\geq 10$ times, 2 points for 5 to 9 times, and 1 point for $\leq 4$ times; nasal itch: 3 points for hard toleration, but ant crawling but can tolerate 2 points Intermittent nasal itch was 1 point; sneezing: 3 points for 11 times per day, 2 points for 6 to 10 times per day, and 1 point for 3 to 5 times per day [4]. (2) Efficacy was evaluated according to the total score improvement rate of symptoms such as runny nose, nasal itching, sneezing, and nasal obstruction in patients with allergic rhinitis, and the total symptom improvement rate $=$ (pre-treatment score - post-treatment score) $/$ pre-treatment score $\times 100 \%$. After 2 weeks of treatment, the degree of lesions did not improve, and the improvement rate of symptoms was less than 20\%; the lower armor swelling was relieved, and the degree of lesions was significantly relieved before treatment. The symptom improvement rate was $20 \%$ to $50 \%$ for improvement; the lower armor swelling was significantly reduced, and the nasal mucosa was reduced. [5]. Total efficiency $=($ good + significant $) /$ total number of cases $\times 100 \%$.

\subsection{Observation Indicators.}

(1) Treatment effect. (2) Changes in scores of sneezing, nasal itching, and salivation before and after treatment for 2 weeks. (3) Changes of serum lgE, Th1/Th2 levels before treatment and after 2 weeks of treatment. (4) Adverse reactions.

\subsection{Statistical Analysis.}

The data was analyzed by SPSS19.0. The measurement data was represented by ( $\pm \mathrm{s})$. The t test was used to represent $\mathrm{n}(\%)$ count data, and the $\chi 2$ test, $\mathrm{P}<0.05$ indicated significant difference. 


\section{Results}

\subsection{Efficacy.}

The total effective rate $(95.24 \%)$ in the observation group was higher than that in the control group (75.61\%) $(\mathrm{P}<0.05)$. See Table 1.

Table 1 Comparison of treatment effects between two groups [n(\%)]

\begin{tabular}{|c|c|c|c|c|c|}
\hline Groups & $\begin{array}{l}\text { Number of } \\
\text { cases }\end{array}$ & invalid & Improve & Significantly & $\begin{array}{l}\text { Total } \\
\text { efficiency }\end{array}$ \\
\hline $\begin{array}{l}\text { Observation } \\
\text { group }\end{array}$ & 42 & $2(4.76)$ & $10(23.81)$ & $30(71.43)$ & $40(95.24)$ \\
\hline Control group & 41 & 10 (24.39) & 11 (26.83) & $20(48.78)$ & $31(75.61)$ \\
\hline$\chi^{2}$ & l & / & l & / & 6.463 \\
\hline$P$ & / & I & / & I & 0.011 \\
\hline
\end{tabular}

\subsection{Symptom Scores.}

Compared with the control group after 2 weeks of treatment, the scores of sneezing, nasal itching, and salivation symptoms were lower in the observation group $(\mathrm{P}<0.05)$. See Table 2.

Table 2 Comparison of the scores of the two groups ( \pm s, points)

\begin{tabular}{|c|c|c|c|c|c|}
\hline time & Groups & $\begin{array}{l}\text { Number of } \\
\text { cases }\end{array}$ & sneeze & Rogue & $\begin{array}{l}\text { Nasal } \\
\text { itching }\end{array}$ \\
\hline \multirow{4}{*}{$\begin{array}{l}\text { Before } \\
\text { treatment }\end{array}$} & $\begin{array}{l}\text { Observati } \\
\text { on group }\end{array}$ & 42 & $1.90 \pm 0.20$ & $2.19 \pm 0.45$ & $2.10 \pm 0.30$ \\
\hline & $\begin{array}{l}\text { Control } \\
\text { group }\end{array}$ & 41 & $1.89 \pm 0.19$ & $2.20 \pm 0.40$ & $2.13 \pm 0.20$ \\
\hline & $t$ & / & 0.233 & 0.107 & 0.535 \\
\hline & $P$ & / & 0.816 & 0.915 & 0.594 \\
\hline \multirow{4}{*}{$\begin{array}{l}\text { After } 2 \\
\text { weeks of } \\
\text { treatment }\end{array}$} & $\begin{array}{l}\text { Observati } \\
\text { on group }\end{array}$ & 42 & $0.52 \pm 0.21$ & $0.99 \pm 0.26$ & $0.70 \pm 0.40$ \\
\hline & $\begin{array}{l}\text { Control } \\
\text { group }\end{array}$ & 41 & $1.01 \pm 0.13$ & $1.70 \pm 0.32$ & $1.30 \pm 0.39$ \\
\hline & $t$ & / & 12.745 & 11.107 & 6.917 \\
\hline & $P$ & I & 0.000 & 0.000 & 0.000 \\
\hline
\end{tabular}

\subsection{Serum Lge, Th1/Th2 Levels.}

After 2 weeks of treatment compared with the control group, serum lgE levels were lower in the observation group, and Th1/Th2 levels were higher $(\mathrm{P}<0.05)$. See Table 3.

Table 3 Comparison of serum lgE, Th1/Th2 levels ( \pm s)

\begin{tabular}{llllll}
\hline & $\begin{array}{l}\text { Num } \\
\text { ber }\end{array}$ & \multicolumn{1}{l}{$\operatorname{lgE}(\mathrm{kIU} / \mathrm{L})$} & \multicolumn{3}{c}{ Th1/Th2 } \\
\cline { 4 - 6 } & $\begin{array}{l}\text { of } \\
\text { case } \\
\text { sroups }\end{array}$ & Before treatment & $\begin{array}{l}\text { After 2 weeks of } \\
\text { treatment }\end{array}$ & $\begin{array}{l}\text { Before } \\
\text { treatment }\end{array}$ & $\begin{array}{l}\text { After } \\
\text { weeks of } \\
\text { treatment }\end{array}$ \\
\hline $\begin{array}{l}\text { Observation } \\
\text { group }\end{array}$ & 42 & $122.30 \pm 35.54$ & $59.20 \pm 26.82$ & $0.80 \pm 0.25$ & $1.35 \pm 0.47$ \\
$\begin{array}{l}\text { Control } \\
\text { group }\end{array}$ & 41 & $123.50 \pm 34.08$ & $79.30 \pm 25.57$ & $0.79 \pm 0.24$ & $0.90 \pm 0.33$ \\
$t$ & $/$ & 0.157 & 3.493 & 0.186 & 5.037 \\
$P$ & $/$ & 0.876 & 0.001 & 0.853 & 0.000 \\
\hline
\end{tabular}




\subsection{The Adverse Incidence.}

The reactions in the adverse reactions observed group (11.90\%) compared with the control group (7.32\%), the difference was not statistically significant ( $\mathrm{P}>0.05)$. See Table 4.

Table 4 Comparison of the incidence of adverse reactions [n (\%)]

\begin{tabular}{lllllll}
\hline Groups & $\begin{array}{l}\text { Number of } \\
\text { cases }\end{array}$ & $\begin{array}{l}\text { feel sick } \\
\text { vomit }\end{array}$ & and & Weary & headache & $\begin{array}{l}\text { Incidence } \\
\text { adverse reactions }\end{array}$ \\
\hline $\begin{array}{l}\text { Observati } \\
\text { on group }\end{array}$ & 42 & $2(4.76)$ & $2(4.76)$ & $1(2.38)$ & $5(11.90)$ \\
$\begin{array}{l}\text { Control } \\
\text { group }\end{array}$ & 41 & $0(0.00)$ & $2(4.88)$ & $1(2.44)$ & $3(7.32)$ \\
$\chi^{2}$ & $/$ & $/$ & $/$ & $/$ & 0.113 \\
$P$ & $/$ & $/$ & $/$ & $/$ & 0.737 \\
\hline
\end{tabular}

\section{Discussion}

Allergic rhinitis has no cure at present, and it mainly uses western medicines such as anti-leukotriene and anti-histamine drugs to relieve symptoms such as stuffy nose and nasal itching, and it is difficult to achieve the effect of treating both the symptoms and the symptoms. The motherland medicine believes that allergic rhinitis is mainly caused by the loss of lung, spleen and kidney, loss of lung qi, health watch, no solid, invasion of foreign pathogens, blood stasis, etc. [6]. "Tai Ping Sheng Hui Fang” records: "The lungs pass through the nose...the gas rides on the nose, so the body fluid flows...”; "Su Wen • Xuan Ming Wu Qi” said: “The kidney is owed. Therefore, the harmony of business and health, solid form Qi, Xuantong nasal discharge for its treatment of the fundamental.

Xinqi granules have the effect of replenishing qi-solid form and expelling wind through phlegm. It is better for the treatment of nasal itch and sneezing caused by the insufficiency of lung qi and external invasion of wind pathogens. However, the treatment cycle is long and the short-term effect is not ideal. It needs to be combined with other drugs. Self-made Guiping Tongqiao Tang is a Chinese herbal decoction composed of windproof, cassia twig, white peony root, magnolia, astragalus, atractylodes, asarum and other multi-flavored Chinese herbal medicines. Fangzhong Wind, Astragalus and Atractylodes Rhizome have the effect of removing wind and solid. Spleen and lung qi; Asarum function in warming the lungs and drinking, hurricane through the wind; white peony and cassia twig have the effect of reconciling the Guardian; Xanthium sibiricum and wolfberry are longer than Tongyu and dispelling the cold, "Compendium of Herbal Medicine" says: "Good. Sweating, dispersing rheumatism, ... treating headaches, nasosinusitis, white peony, phlegm, licorice, licorice, and various drugs; various phases of drug use, and sharing of phlegm, qi, solidification, and reconciliation. Modern pharmacology believes that the main components of cocklebur, windbreak, Asarum, cassia twig have anti-histamine, anti-inflammatory, anti-allergic, antipyretic, inhibition of acetylcholine, can stabilize the mast cell membrane, inhibit media release, only Asarum It can reduce the total allergic media release of guinea pig allergies by more than $40 \%$, thereby reducing the inflammatory response and regulating the body's immunity [7]. When used in combination with Xinqin granules, it can exert synergistic effects among drugs and increase mutual efficacy, and improve nasal congestion together. This study found that the total effective rate of treatment in the observation group was higher than that in the control group. The scores of sneezing, nasal itching, and salivation symptoms were lower in the observation group than in the control group after 2 weeks of treatment $(\mathrm{P}<0.05)$. Rhinitis has a remarkable effect and can significantly improve the symptoms of nasal itching and sneezing in patients.

In addition, studies have pointed out that allergic rhinitis is IgG-mediated chronic inflammatory lesions of the nasal mucosa, specific antigens stimulate the nasal mucosa, resulting in antigen-presenting cells transmit antigenic peptide signals, promote the proliferation of Th2 cells, a large number of Th1 cells, resulting in Th1 /Th2 imbalance, resulting in the body's immune 
dysfunction, a large number of release of interleukin-6 and other inflammatory cytokines, involved in the process of inflammation of the nasal mucosa, resulting in increased nasal permeability of the capillaries, promote glandular secretion, causing sneezing A series of allergic symptoms such as nasal itching [8]. Therefore, correcting imbalance of Th1/Th2 ratio and regulating lgE level are important targets for clinical treatment of allergic rhinitis. This study found that serum lgE levels in the observation group after 2 weeks of treatment were lower than those in the control group, and Th1/Th2 levels were higher than those in the control group $(\mathrm{P}<0.05)$. Self-made Guiping Tongyu Decoction combined with Xinqi granules can improve serum lgE in patients with allergic rhinitis. At the same time, the study found that the incidence of adverse reactions in both groups was low, showing that the use of Xin Qi granules on the basis of treatment of allergic rhinitis plus Gui Ping Tong Yu soup does not increase the incidence of adverse reactions, combined with safe and reliable.

In summary, Guiping Tongyu Decoction combined with Xinqi Granules has been applied to patients with allergic rhinitis with significant effects, mainly manifested in the improvement of patients' symptoms, serum lgE levels, and elevated levels of serum Th1/Th2. The combination therapy is safe and reliable.

\section{References}

[1] Chen Tingting, Liu Fanghui. Therapeutic effect of acupuncture sphenopalatine ganglion on allergic rhinitis [J]. Shanghai Journal of Acupuncture and Moxibustion, 2016, 35(7):850-852.

[2] Wang Shuying. Clinical observation on the treatment of allergic rhinitis with Mahuang Fuzi Asacin Decoction [J]. Shaanxi Traditional Chinese Medicine, 2015, 36(2): 188-189.

[3] Huang Xuanzhao, Wang Jibao. Practical Otolaryngology [M]. Beijing: Beijing People's Medical Publishing House, 2000: 255-264.

[4] Yao Shouguo. Observation of the efficacy of self-made Cang Er Yu Ping Decoction in the treatment of allergic rhinitis [J].Chinese Journal of Traditional Medical Science and Technology, 2015, 22(3):309-310.

[5] Gao X, Chen QJ, Luo J, et al. Therapeutic effect of pidotimod combined with loratadine on allergic rhinitis in children [J]. Modern Journal of Integrated Traditional Chinese and Western Medicine, 2016, 25(17): 1845-1847.

[6] Shang Wanbiao. Gegen Decoction for the treatment of allergic rhinitis [J]. Clinical Research of Traditional Chinese Medicine, 2016, 8(23):37-38.

[7] Liu Zhe. Meta-analysis of the clinical efficacy of traditional Chinese medicine for allergic rhinitis and its safety evaluation [D]. Chengdu University of Chinese Medicine, 2015.

[8] Li Qiaoyu, Zheng Guoxi. Effect of budesonide nasal spray on Th1/Th2 cytokines in patients with allergic rhinitis and observation of curative effect [J]. Hebei Medical Journal, 2016, 22(4):538-540. 